This is the pre-print version, prior to peer review. For the final version of record see: http://onlinelibrary.wiley.com/doi/10.1111/area.12409/full

\title{
The contingencies of purposeful co-production: Researching new migrant employment experiences in the North East of England
}

John Clayton, Northumbria University, UK

Tom Vickers, Nottingham Trent University, UK

\section{Abstract}

This paper presents methodological reflections from a programme of empirical research across two distinct but related projects, which culminated in an examination of the employment experiences of new migrants in the North East of England. This mixed-methods research focussed on the position and experiences of migrants from the Eastern European countries joining the EU in 2004 and 2007, and refugees and asylum seekers from a broad range of countries. Co-produced by an inter-disciplinary academic team, migrants living and working in the region and voluntary sector organisations involving and supporting migrants, the research looked to address gaps in evidence to support education, advocacy and service provision. The paper argues that while co-production has tremendous potential to traverse the borders of theory and action in pursuit of positive change in people's lives, careful consideration needs to be given to distinct incarnations and the manner in which co-production emerges through specific conditions and relationships. We identify the principles underpinning this research, but also illustrate how our approach developed over time into a form of distributed-resource, which was able to connect organisations, people and financial resources from varied sources around shared values and an interest in outcomes.

\section{Introduction}

This paper contributes to debates around co-produced research (Mason, 2015) and the challenges of conducting research with marginalised communities (Goodman and Phillimore, 2012), by reflecting on a programme of research culminating in an examination of the employment experiences of new migrants in the North East of England. The research - designed, conducted, disseminated and refined through an inter-disciplinary and cross-sectoral partnership - looked to address evidence gaps regarding the experiences of migrant groups, thus contributing to education, advocacy and service provision. This is of particular significance in a peripheralised region impacted by uneven development (Hudson, 2005), austerity (Clayton et al, 2016) and experiencing relative demographic change (Rienzo and Vargas-Silva, 2016). Rather than highlighting this as a model, we emphasise both the importance of the principles of co-production and the realities of research which threw up a number of contingent structural and practical challenges. 
This is the pre-print version, prior to peer review. For the final version of record see: http://onlinelibrary.wiley.com/doi/10.1111/area.12409/full

The paper opens by discussing intersecting concepts of co-production. We then outline the background and methodology, indicating the emergent character of coproduction. With reference to key relationships and research directions, we then consider challenges faced and responses to them. In an era where collaboration is championed as a remedy to socio-economic challenges and a demonstration of relevance (Armstrong and Allsop, 2010), careful consideration must be given to distinct incarnations in specific conditions through which co-production takes shape. We identify the approach emerging in this case as one of distributed-resource, which connected organisations, people and resources from varied sources around shared values and an interest in outcomes.

\section{Purposes and principles of co-production}

In focussing on relevant aspects of co-production, we make a distinction, yet not separation, between (a) co-production in the delivery of public services and (b) coproduction as research practice. Coined by Ostrom and Baugh (1973), co-production in the former sense related to active citizen participation, specifically in crime reduction in the US. Building on this from a civil rights perspective, Cahn (2004) highlighted the role of non-market economies in revealing 'limitations of government efforts to empower people for whom the market had no use' (Stephens et al 2008: 1) - with attention to time banking. More recently in the UK, as the role of the state in the design and delivery of public services has been challenged, co-production characterises new governance networks (Rhodes, 1996), through which the production and consumption of services are increasingly inseparable (Bovaird, 2012).

Bovaird (2007) suggests this has resulted in some positive outcomes including the widening of choice based upon personal experience, a transfer of power from professionals and the mobilization of alternative social capital. On the other hand, he highlights that contestations may emerge due to differing values and unclear responsibilities, that the capacity of non-state actors to retain independence may be undermined, and that public accountability may be compromised. Questions also remain regarding who gets included and how, as well as the differential desire to become involved in prolonged relationships. More critically, it can be viewed as a manifestation of neoliberal logics; a transfer of risk and responsibility to communities in an era where the state as a vehicle for economic development and social welfare is undermined. There are then both democratic possibilities, but also limits when imposed through prevailing discourses such as austerity.

There are clear parallels with co-production when viewed as research practice. Specifically, the disruption of established power relations and questions regarding the locus of expertise. In this case with regard to research relations that are more 
This is the pre-print version, prior to peer review. For the final version of record see: http://onlinelibrary.wiley.com/doi/10.1111/area.12409/full

horizontal than in conventional objectivist research (Pearce, 2008). However, there are also connections in terms of the challenges of participation related to resource, inclination, conflict/consensus, risk and responsibility.

Co-production as research practice is far from recent (Chambers 1994). Historical attempts to ensure research works beyond the academy, alongside more reflexive understandings of the positions of researchers/researched, are many and varied. This includes the work of social phycologists such as Lewin (Adelman, 1993), geographers such as Bunge (Fuller and Kitchen, 2004), the writings of popular educators like Freire (1970) and feminist scholars drawing attention to power imbalances within and beyond academia (Women and Geography Study Group, 1997). More recently, as part of a 'participatory turn' towards the democratisation of the research process (Gilchrist et al, 2015) those advocating a Participatory Action Research (PAR) approach have offered crucial contributions (Pain 2007). PAR looks to work with research participants (Heron and Reason, 2001) towards transformative research outcomes that advance causes, address problems raised by communities and bring tangible benefit.

In a context where issues of 'relevance' and 'usefulness' are increasingly in the spotlight (Armstrong and Allsop, 2010), there has been increasing interest in coproduction. In part, this reflects the 'impact agenda' of the UK Research Excellence Framework (REF), but is also in spite of it (Askins and Mason, 2015). Instrumental attention to co-production is problematic (Slater, 2012), but a renewed focus opens the door to a fresh consideration of its imperatives. This is exemplified in continued attention to issues of public engagement and dialogue beyond the university in both sociology (Burawoy 2003) and geography (Fuller 2008).

In line with many of the tenets of PAR, Durose et al (2011), suggest co-production is characterised by those outside of academia taking greater control of research, sharing of expertise and working collaboratively towards outcomes that have discernible impact. Despite the clear crossover, Kagan (2013) argues what might distinguish coproduction from PAR is recognition of the variability of participation, whilst retaining an emphasis on collaborative 'sense-making'. Pearce (2008) contends that research with others does not always demonstrate strong participatory features, whilst taking seriously a range of experiential knowledges. Nind (2014) uses the language of 'inclusive research' to commit to democratic, ethical, transparent and emancipatory principles, but exercises caution when thinking about the realities of commitment involved. She stresses the dangers of transferring responsibility onto communities, and that academics should not forget what they might have to offer.

On reflection, our own research emerged around several working principles that speak to aspects of the discussion above: 
This is the pre-print version, prior to peer review. For the final version of record see: http://onlinelibrary.wiley.com/doi/10.1111/area.12409/full

1. People are experts in their own lives and are best positioned to articulate and interpret their experiences.

2. Understandings developed by frontline practitioners and community leaders through accumulated experience, can provide invaluable perspectives with which to contextualise individual experiences.

3. A commitment to public engagement as an iterative process, but beyond that to action aimed at helping to address challenges people face.

4. Commitment to take steps to avoid negative unintended consequences for those involved in the research.

5. To fulfil responsibilities, not just to those more directly involved, but also to wider collective interests.

These principles represent a commitment to collaboration as a means of bringing marginalised voices to the fore and challenging oppression through a unity of theory and action, conceptualised by Freire (1970) as praxis - speaking to some of his concerns around dialogue, conscientization and informed action.

However, recognition of such principles does not mean their application is linear and straightforward. Commitment to participatory and action orientated research rightly sets the bar high, but there is a need to consider the circumstances under which different incarnations might emerge. When conducting research with marginalised communities, a whole range of challenges emerge which entail degrees of adaptation. In this research some of the challenges encountered were structural, some practical, but they were also often emotional. This related to the political and ethical basis of research interests on behalf of academics involved (Gray, 2008), but also crucially to the investments by both those experiencing migration (Boccagnia and Baldassarb, 2015) and those looking to best support the interests of these communities (Clayton et al, 2015).

As Breitbart (2003) recognises, we need to consider what co-produced research might actually entail. This may differ from what research looks like based upon 'impact' criteria. We now outline this as applied to our research.

\section{New migrants in the North East: practicing co-production}

This research looked to establish a better understanding of the position and experiences of new migrants ${ }^{1}$ in North East England. It was mainly focused on the distinct and shared experiences of asylum seekers and refugees (after the UK dispersal policy was initiated in 1999) and economic migrants from post 2004 EU accession

\footnotetext{
${ }^{1}$ Our definition of new migrants refers to those who were not born in the region and had arrived in the UK since 1999.
} 
This is the pre-print version, prior to peer review. For the final version of record see: http://onlinelibrary.wiley.com/doi/10.1111/area.12409/full

states $^{2}$ and included two projects. The first explored day-to-day challenges facing migrants, through a participatory film-making methodology, and the second examined the position and experiences of new migrants within and outside the regional workforce, employing a mixed-methods approach.

The first project was interested in how austerity conditioned daily challenges for migrants in a region suffering disproportionately (Clayton et al, 2016) and where ethnic diversity was relatively not clearly established. ${ }^{3}$ A daylong exploratory workshop was organised via regional third sector organisations and facilitated by the lead academic. This brought together 18 migrants from a variety of migration routes and with various immigration statuses to engage in collective critical reflection (Freire, 1970). Participants discussed issues of concern and ranked these to generate a set of themes for further discussion (principle 1). With the assistance of a professional filmmaker, participants produced short films to illustrate their experiences (Mann, 2006). A further workshop allowed for discussion of the films and connections between them and the workshop. Participants made decisions about how the films should be edited into a montage. Summaries of the workshop discussions were presented alongside the resulting short film to two regional audiences and formed the basis for discussions with regional stakeholders.

There were emotive and critical concerns expressed by some stakeholders including the breadth of this initial focus, the ability of participants to identify connections between personal challenges and broader conditions, the short-term character of the workshop and the suitability of the films as effective mediums to inform policy. In discussion with partners, it was decided to withhold the montage film from further distribution (principles 4 and 5). However, despite these issues, a shared priority emerged in relation to employment. This process also provided an important learning experience for the academics involved, highlighting the importance of the iterative character of co-production (principle 3 ) and informing approaches to the second project.

It became apparent that there was little systematic research addressing employment related concerns in the North East (Stenning and Dawley, 2009; Crossley and Fletcher, 2013). While research had taken place(CoMedia 2005; Fitzgerald 2005; Pillai 2006; Fitzgerald and Hardy 2010), this mostly preceded the economic crisis of 2008. In discussion with two independent third sector partners in the region (Regional Refugee Forum (RRF) and International Community Organisation of Sunderland (ICOS)), who

\footnotetext{
${ }^{2}$ Including Czech Republic, Estonia, Hungary, Latvia, Lithuania, Poland, Slovakia, Slovenia in 2004 and Romania and Bulgaria in 2007. This broadened out during the research, as we encountered a more diversepopulation. Participants came from 59 different countries and a variety of migration routes.

${ }^{3}$ Based on 2014 estimates the proportion of the region's population born outside the UK is now $5.2 \%$
} 
This is the pre-print version, prior to peer review. For the final version of record see: http://onlinelibrary.wiley.com/doi/10.1111/area.12409/full

had raised these issues through previous projects (Fletcher, 2011), a small grant was secured to explore them further. This second more substantial project therefore emerged through a combination of academic interest, pressing issues identified by migrants themselves and those prioritized by organisations within the regional voluntary and community sector (principle 5).

Through discussions around the kind of evidence policy makers would be most receptive to (principle 3), the project employed mixed methods in three stages. Firstly, a questionnaire, completed by 402 migrants, gathered data on employment positions prior to and following arrival in the UK. Questions were refined in consultation with partners and members of an advisory board, including a small pilot. Survey responses were collected face-to-face and through self-completion via support agencies, dropins, migrant community organisations, ESOL classes and workplaces across most of the region.

The second stage involved in depth semi-structured interviews with a diverse sample $(n=27)$ of those who completed the questionnaires (principle 1$)$. An additional seven people were interviewed who had not completed the survey but helped to fill gaps in the data. Six pilot interviews, were also included, making a total sample of 40 . Interviews were conducted by academic members of the research team. Six of the interviews used an interpreter, and were checked by a different translator to ensure accuracy. Wherever possible interview locations were selected that meant participants would not have to travel and were public spaces in which they felt comfortable.

The third stage involved a process of verification and triangulation through in-depth interviews with stakeholders, support organisations and representatives from the public and third sectors ( $n=12$ ) (principle 2). As part of these interviews preliminary findings were presented and interviewees were asked to comment on connections between these findings and their own experiential knowledge.

Following initial analysis and production of a preliminary report, a policy seminar event was organised. This involved a panel session with a range of stakeholders asked to respond to the draft report, followed by workshops around key themes. The event allowed for dissemination of initial findings, but also treated attendees (some of whom were involved in earlier stages) as active participants, rather than passive recipients of knowledge (principle 5). ${ }^{4}$ Workshop discussions allowed for the further verification of findings, as well as drawing upon broader expertise $(n=50)$ in fine tuning

\footnotetext{
${ }^{4}$ All of the interview participants were invited to attend, with travel expenses provided, and some did so. However, an absence of funding for childcare and the timing of the event on a weekday when some people were at work limited participation.
} 
This is the pre-print version, prior to peer review. For the final version of record see: http://onlinelibrary.wiley.com/doi/10.1111/area.12409/full

recommendations (principle 2). Thirdly the seminar offered an opportunity to extend networks between organisations and individuals, including opportunities for participants to meet with those representing support organisations (principle 3). ${ }^{5}$

In the first project there was more of an emphasis on co-production with migrants themselves, but in the second project this shifted towards co-production with partner organisations and a range of other stakeholders in the region. Through this process we increasingly recognised the value of different kinds of expertise as complimentary assisting in the co-production of policy relevant scholarship (principle 2) - but also the reality of commitment involved. We reflect on these issues below.

\section{Intensities of participation and negotiated action}

As Kagan (2013) suggests, co-production represents a spectrum of participation. The first project represented a brief but intensive form of direct participation (Pain and Francis, 2003) - listening to migrant voices as a route to agenda setting.. The primary sources of data for the second project required vital contributions from participants. However, migrants themselves were not strictly 'decision makers' in the direction of the research (Bergold and Thomas, 2012).

The limited scope of the second project based upon our discussions with partners and our advisory board meant that engaging with the participants at every stage was not possible or arguably desirable. It is rightly recognised that inclusive research involves the flattening of hierarchies of power (White et al, 2004). However, attempts to bring participants on board to the point of them becoming 'co-researchers' would have been partial, but also potentially exploitative (Campbell and Vanderhoven, 2016). This is particularly true for those whose lives were often constrained by finances, time and other resources (Vickers et al, 2016).

Rather, for this research at this stage, the central practical relationship was with the two organisations previously mentioned, our advisory board and other external organisations in the voluntary and community sector. Whilst established with their own aims and priorities, these organisations were not external to migrant communities. Rather in many ways they were constitutive of them - providing a voice for and often run by members of those communities. We therefore need to be cautious when calculating what 'authentic' co-production looks like. The role of partners was crucial in providing an insight into the dominant pressures faced. Not only did this add to the quality and quantity of data generated, but it also provided an insight into practical relevance. A further layer of complexity was present, as in

\footnotetext{
${ }^{5}$ This seems especially important, since the research indicated that awareness of support organisations amongst participants was low (54\%).
} 
This is the pre-print version, prior to peer review. For the final version of record see: http://onlinelibrary.wiley.com/doi/10.1111/area.12409/full

defining 'new migrants' we identify a heterogeneous population, who nevertheless share experiences. Collaborating with partners from organisations working in different ways with different (yet intersecting) communities (one more focussed on the needs of asylum seekers and refugees and the other more focussed - but not exclusively - on the needs of EU migrants) helped in creating a dialogue around these experiences.

To claim co-production is an entirely smooth process is of course disingenuous. As Jung et al (2012) demonstrate there are a number of potential tensions including levels of engagement, expectations, clarity over roles, unsought for results and the potential use of those results. The first project was marked by some of these - such as which issues should be emphasised, how experiences should be communicated and responsibility for the research. In order to learn from this an independent chair was appointed to the advisory group and terms of reference were agreed to establish common understanding (Jung et al, 2012). The emphasis fell on where priorities and interests overlapped (Finney and Risbeth, 2006).

Underpinning the agreement was recognition of different forms of expertise members of the team could offer, but also recognition of the different priorities and constraints on those involved. For the academics, there were responsibilities in meeting the requirements of the grant and expectations of outputs in accepted academic formats. For the non-academic partners the key priority was with producing outputs that aligned with their objectives, filled the gaps in data that enhanced advocacy, whilst not compromising those they supported. A principle of partnership and ongoing discussion was adopted, whilst recognising contributions would vary. This also allowed for the possibility of independence in the interpretation of data collected if required. In addition, the preliminary report and policy seminar presentation did not offer definitive conclusions or recommendations to avoid presumptions. Rather, findings were discussed in a provisional format and event participants were asked to discuss and actively co-design recommendations.

Despite the desire of third sector partners to play an active role in the research, there were other factors that influenced the character of their engagement. Recent years have seen severe curtailment of access to funding in the region (Clayton et al, 2015). This has acted as a brake upon some forms of participation and limited involvement to more advisory roles. As one partner indicated, for their organisation and for those who contribute time and effort voluntarily, the squeeze on/disappearance of funding, particularly Core Funding and other policy reforms have had a considerable impact. .

Most pressing was staff time and availability (Campbell and Vanderhoven, 2016), especially as our partners were working with those whose needs were often urgent. 
This is the pre-print version, prior to peer review. For the final version of record see: http://onlinelibrary.wiley.com/doi/10.1111/area.12409/full

There were funds available to our partners to conduct certain activities, although these were limited due to the scale of the bid and, as with academic staff, did not cover staffing costs. Where this is the case, organisations must assess whether the time input required matches the outcomes for which the organisation is funded. This raises the question of what we (as academics) are able to ask of external organisations and whether our expectations are reasonable. It also allows us to see that forms of co-production are contingent upon the policy context in which partners operate, sometimes resulting in uneven, yet still crucial engagement.

This project also involved working with colleagues across disciplines. Initially a sociologist and a geographer constituted the academic team, but this expanded to include those in Law and Business with interests in migrant self-employment and other research staff who became involved in data analysis and the organisation of dissemination activity. There has been considerable attention to the competing orientations of partners inside and outside of academia (Breitbart, 2003), but less to the participation of academic partners. In spite of different disciplinary traditions, shared links to practice-related research and interest in dimensions of migrants' working lives were most important. Challenges related to structural and practical limitations on participation.

Within UK post-1992 Universities - home to staff with different career trajectories and levels of engagement with research cultures, there are challenges for both finding time to research and to work collaboratively (Moore, 2003), challenges which are also gendered (Grant and Knowles, 2000). Certain roles were more prohibitive for some staff, especially those arriving later in the project, less experienced in conducting research and working to part-time contracts with heavy teaching workloads. This particularly reduced capacity to contribute to more strategic discussions and at certain points it was difficult to involve all members in decision making.

With regard to contributions made by both academics and 'external' partners, the second project shifted over its course from one concentrated on working intensively with a small number of individuals and organisations to one engaged with a wider range of organisations and drew upon a range of expertise and labour. That we could communicate through trusted organisations who had both professional and affective investments in these issues was crucial in relation to data collection and the refinement of the findings. For example, there was no funding to translate questionnaires but we were able, to some extent, to address a lack of participants with lower levels of English by asking intermediaries with appropriate skills to help. Organisations involved in data collection both welcomed the need for the research, encouraging participation, and also acted in a protective role by holding the research 
This is the pre-print version, prior to peer review. For the final version of record see: http://onlinelibrary.wiley.com/doi/10.1111/area.12409/full

team to account and making important decisions such as who they felt might be appropriate participants. ${ }^{6}$

To supplement the small grant received from the British Academy/Leverhulme Trust, we also sourced small pots of money from our respective departments to enhance the project, for example through incentives and additional staffing to contribute to analysis. Effectively the project became a distributed-resource ${ }^{7}$ project, one characterised by a number of dispersed contributions to achieving a shared goal. Of course such contributions were made in good faith and therefore carried a tremendous responsibility to ensure the research was beneficial. This became a necessary practical aspect of the project in order to achieve its objectives, but was also underpinned by principles for more rigorous, inclusive and public research.

\section{Conclusions}

This paper raises questions of who gets involved and how they get involved in coproduced research, drawing on a research project interested in employment experiences of new migrants in North East England. We highlight this as a reflection on the challenges and contingencies of such a process. For this research there were a number of structural and practical dimensions: responses to earlier critiques and discussions regarding the direction of the research; the requirements for specific data; the scale of the project; the character of the organisations involved; the issues at stake and the broader constraints acting on all 'producers'. In addition it is important to recognize many of the challenges faced were also deeply affective-revolving around the relationships, investments and emotional labour whilst attempting to maintain an 'equal conversation' (Nind, 2014).

It is clear then that there is not one uniform, 'pure' or ready-made form of coproduction (Breitbart, 2003: 175). For this research, different elements and intensities of participation by migrant communities, partners and other stakeholders were involved at different stages. This was a result of ongoing negotiations between a range of actors, which came down to what we had in common and what we are able to contribute. Of course, this raises questions about whose voices get heard and how research may take different courses dependent on the identity of academic and nonacademic partners - categories which are too broad to generalise across. Through reflexive approaches informed by the principles outlined earlier, there was a largely successful attempt here to balance and layer contributions. While individual migrants

\footnotetext{
${ }^{6}$ Through ESOL classes, the surveys were welcomed as a useful learning aid for developing English language skills and in some cases were incorporated into classes..

${ }^{7}$ As in a distributed computing system in which components located on networked computers communicate and coordinate their actions by passing messages. The components interact with each other in order to achieve a common goal.
} 
This is the pre-print version, prior to peer review. For the final version of record see: http://onlinelibrary.wiley.com/doi/10.1111/area.12409/full

themselves were not the primary co-producers, in the final instance their voices and experiences were centre stage.

Co-production also varied in the form of process and product. Nind (2014) suggests, that while important, emphasis placed on the process of inclusive research may lead to neglect of what emerges from it. One of the principles guiding this work was a sense of responsibility both to direct participants, but also to broader collective interests. Co-production as product was particularly important in providing an enhanced evidence base. The manner in which the research was disseminated, but also refined through stakeholder participation also allowed for dialogue between academia, the third sector and the policy and funding realm to be reinforced. This included feeding into networks on the advice of our partners that included representatives from government departments about how issues raised could be taken forward.

Academic and non-academic partners can sustain mutual benefit from working together, both as a result of financial and political pressures, but also to address shared concerns. We emphasise that collaboration, even when based around principles of co-production, entails a certain 'messiness', which to some extent should be valued for providing new insights (Cook, 2009), but which also speaks to the constraints acting upon such work. Recognition of this can only facilitate more effective co-production that is in the interests of those at the sharp end.

\section{References}

Adelman C 1993 Kurt Lewin and the Origins of Action Research, Educational Action Research 11 7-24

Armstrong F and Alsop A 2010 Debate: Co-production can contribute to research impact in the social sciences Public Money \& Management 304 208-210

Askins K and Mason K 2015 Us and Us: Agonism, Non-Violence and the Relational Spaces of Civic Activism ACME: An International Journal for Critical Geographies 142

Clayton J, Donovan C and Merchant J 2015 Emotions of austerity: care and commitment in public service delivery in the North East of England Emotions, Space and Society 14 24-32

Clayton J, Donovan C and Merchant J 2016 Distancing and limited resourcefulness: third sector service provision under austerity localism in the North East of England Urban Studies 53 723-40

Bergold J and Thomas S 2012. Participatory Research Methods: A Methodological Approach in Motion Forum Qualitative Sozialforschung / Forum: Qualitative Social Research 131 
This is the pre-print version, prior to peer review. For the final version of record see: http://onlinelibrary.wiley.com/doi/10.1111/area.12409/full

Boccagnia P and Baldassarb L 2015 Emotions on the move: Mapping the emergent field of emotion and migration Emotion, Space and Society 16 73-80

Breitbrat M M 2013 Participatory research methods in Clifford N J and Valentine G eds Key Methods in Geography Sage London 161-178

Burawoy M 2003 Public sociologies Social Forces 82 1603-18

Cahn E 2004 No more throwaway people: the co-production imperative Washington DC Essential Books

Campbell H and Vanderhoven D 2016 N8/ESRC Research Programme: Knowledge That Matters: Realising the Potential of Co-Production Economic and Social Research Council

Chambers R 1994 The Origins and Practice of Participatory Rural Appraisal World Development 47 953-969

CoMedia 2005 The Intercultural City: making the most of diversity - A study for One North East into The Attraction and Retention of Migrants to the Tyne and Wear City Region.

Cook T 2009 The purpose of mess in action research: building rigour though a messy turn Educational Action Research 172 227-291

Crossley S and Fletcher G 2013 Written out of the picture? The role of local services in tackling child poverty amongst asylum seekers and refugees, North East Child Poverty Commission and Regional Refugee Forum North East.

Dowling R 2008 Geographies of identity: labouring in the 'neoliberal' university. Progress in Human Geography 1-9

Durose C Beebeejaun Y Rees J Richardson J and Richardson L 2011 Towards coproduction in research with communities: Scoping study report to AHRC Connected Communities Programme AHRC Swindon www.ahrc.ac.uk/FundingOpportunities/Pages/connectedcommunities.aspx

Finney N and Rishbeth C 2006 Engaging with Marginalised Groups in Public Open Space Research: The Potential of Collaboration and Combined Methods Planning Theory \& Practice 71 27-46

Fitzgerald I 2005 Migrant Workers in the North East of England Northern TUC and Northumbria University. 
This is the pre-print version, prior to peer review. For the final version of record see: http://onlinelibrary.wiley.com/doi/10.1111/area.12409/full

Fitzgerald I and Hardy J $\mathbf{2 0 1 0}$ 'Thinking Outside the Box'? Trade Union Organising Strategies and Polish Migrant Workers in the United Kingdom British Journal of Industrial Relations 481 131-150

Fletcher G 2011. Skilled: Finding routes for Refugees to use their skills and experience and contribute to the North East region's economic future Regional Refugee Forum North East

Freire P 1970 Pedagogy of the Oppressed Continuum London

Fuller D 2008 Public geographies: taking stock Progress in Human Geography 1-11

Fuller D and Kitchen R Ed 2004 Radical theory/critical praxis: making a difference beyond the academy? 1-20 Praxis (e)press

Gilchrist P Holmes C Lee A Moore N and Ravenscroft N 2015 Co-designing nonhierarchical community arts research: the collaborative stories spiral Qualitative Research Journal $154459-471$

Goodman L and Phillimore J Eds 2012 Community research for participation: From theory to method Policy Press Bristol

Grant B and Knowles S 2000 Flights of imagination: academic women becoming writers, International Journal of Academic Development 51 6-19

Gray B 2008 Putting Emotion and Reflexivity to Work in Researching Migration, Sociology 425 935-952

Heron J and Reason P 2001 The Practice of Co-operative Inquiry: Research with rather than on people in Reason $\mathrm{P}$ and Bradbury $\mathrm{H}$ eds Handbook of Action Research: Participative Inquiry and Practice Sage London 179-188

Hudson, R. 2005 Rethinking change in old industrial regions: reflecting on the experiences of North East England Environment and Planning A 37 581-596

Jung T Harrow J and Pharoah C 2012 Co-producing research: working together or falling apart? CGAP Briefing Note 8 http://www.cgap.org.uk/uploads/Briefing\%20Papers/CGAP\%20Briefing\%20Note\%20 8\%20-\%20Co-producing\%20research.pdf

Kagan C 2013 Co-production of research: for good or ill? Edge Hill University, http://espace.mmu.ac.uk/609524/1/Co\%20production\%20reserach\%20ormskirk\%20 b\%2013.pdf 
This is the pre-print version, prior to peer review. For the final version of record see: http://onlinelibrary.wiley.com/doi/10.1111/area.12409/full

Mann K 2006 Connecting Futures Through Film: The evaluative story of the focUS connecting futures participatory video project ICAR London

http://icar.livingrefugeearchive.org/ConnectingFuturesThroughFilm.pdf

Mason K 2015 Participatory Action Research: Coproduction, Governance and Care. Geography Compass 9 497-507

Moore S 2003 Writers' retreats for academics: exploring and increasing the motivation to write Journal of Further and Higher Education 27 333-342

Nind M 2014 What is inclusive research? Bloomsbury London

Ostrom E and Baugh W H 1973 Community Organization and the Provision of Police Services Beverly Hills Sage

Pain R and Francis P 2003 Reflections on participatory research Area 35 46-54

Pain R 2007 Participatory action research approaches and methods: Connecting people, participation and place Routledge London

Pearce J 2008 We Make Progress Because We are Lost': Critical Reflections on Coproducing Knowledge as a Methodology for Researching Non-Governmental Public Action, Non-Governmental Public Action Programme Working Paper 27, http://www.Ise.ac.uk/internationalDevelopment/research/NGPA/publications/WP2 7 Methods Pearce Web.pdf

Pillai R 2006 Destination North East? Harnessing the regional potential of migration IPPR North

Rienzo C and Vargas-Silva C 2016 Migrants in the UK: An overview Migration Observatory University of Oxford http://www.migrationobservatory.ox.ac.uk/wpcontent/uploads/2016/04/Briefing-Migrants UK Overview.pdf

Rhodes R A W 1996 The New Governance: Governing without Government, Political Studies 44 652-667

Slater T 2012 Impacted geographers: a response to Pain, Kesby and Askins. Area, 44 $1117-119$

Stephens L Ryan-Collins J and Boyle D 2008 Co-production: a manifesto for growing the core economy London New Economics Foundation

Vickers T, Clayton J, Davison H, Hudson L, Cañadas M A, Biddle P, Lilley S, Fletcher G and Chantkowski M 2016 'New migrants' in the north east workforce: final report Nottingham Trent University, Nottingham 
This is the pre-print version, prior to peer review. For the final version of record see: http://onlinelibrary.wiley.com/doi/10.1111/area.12409/full

White G Suchowierska M and Campbell M 2004 Developing and systematically implementing participatory action research, Archives of Physical Medicine and Rehabilitation, 852 S3-S12

Women and Geography Study Group 1997 Feminist Geographies: Explorations in Diversity and Difference Longman Harlow 